Kevin Wibawa1 ${ }^{1}$ Ferica Valentine Kuhuwael ${ }^{2}$, Caesar Rio Julyanto Putra1, Sandra Utami Widiastuti², Leonardo Paskah Suciadi ${ }^{3}$

${ }^{1}$ Research Associates, Siloam Heart Institute, Jakarta, Indonesia

${ }^{2}$ Internal Medicine, Siloam Hospitals Kebon Jeruk, Jakarta, Indonesia

${ }^{3}$ Cardiology and Vascular Medicine, Siloam Heart Institute / Siloam Hospitals Kebon Jeruk, Jakarta, Indonesia

\title{
Euglycemic diabetic ketoacidosis associated with empagliflozin in patients hospitalized with acute pulmonary embolism
}

\section{ABSTRACT}

Euglycemic diabetic ketoacidosis (Eu-DKA) is a rare but life-threatening complication in diabetic patient treated with sodium-glucose cotransporter 2 inhibitors (SGLT2i). A 71-year-old diabetic female treated with empagliflozin presented to the ED with shortness of breath. Diagnosis of acute pulmonary embolism was confirmed initially. She was treated conservatively with subcutaneous enoxaparin $60 \mathrm{mg}$ bidaily. and oxygen therapy. Respiratory distress associated with anion gap - metabolic acidosis and ketosis developed on the following days however her blood glucose levels were always within normal limit. Clinical recovery was gained after stopping the drug, administering rehydration, and insulin drip. Complication of DKA without hyperglycaemia should be considered while evaluating ketoacidosis in diabetic patients treated with SGLT2i, particularly in critical illness cases. (Clin Diabetol 2021; 10; 2: 204-208)

Key words: euglycemic diabetic ketoacidosis, diabetes mellitus, SGLT2i, empagliflozin, acute pulmonary embolism

\section{Introduction}

Diabetic ketoacidosis (DKA) is an acute lifethreatening complication of diabetes. It is classically characterized as a clinical triad comprising anion-gap metabolic acidosis, hyperglycemia and increased ketone bodies in the blood and urine. Typically, plasma glucose level is $>250 \mathrm{mg} / \mathrm{dL}$ in DKA. This situation is usually triggered by other critical illness or infection. However, it is also reported that DKA could occur in a subset of patients with the serum glucose levels within the normal limits, termed as euglycemic DKA (Eu-DKA) [1].

Sodium glucose co-transport 2 inhibitors (SGLT2i) is a novel class of antidiabetic medications which act as insulin-independent glucose lowering agents by blocking selectively the SGLT2 in renal tubules, resulting in glucose elimination by urine. Rare side effect of Eu-DKA associated with this agent has been recently reported [2].

Here we describe a case of Eu-DKA which occurred in a diabetic patient treated with empagliflozin who was hospitalized du to acute pulmonary embolism.

\section{Case illustration}

A 71-year-old female admitted to emergency room (ER) with symptoms of progressive malaise and shortness of breath since the last several days. She had experienced recurrent thromboembolism events in the past 6 months including deep vein thrombosis (DVT) at the right lower extremity and acute pulmonary embolism. Additionally, she had been diagnosed with a significant coronary artery disease but percutaneous coronary intervention ( $\mathrm{PCl}$ ) was unsuccessful. Her current medications were edoxaban $60 \mathrm{mg} / \mathrm{d}$, empagliflozin $25 \mathrm{mg} / \mathrm{d}$, valsartan $80 \mathrm{mg} / \mathrm{d}$, and atorvastatin 20 
Table 1. Laboratory results at admission

\begin{tabular}{|c|c|c|c|}
\hline Parameters & Value & Reference range & Unit \\
\hline Haemoglobin & 11.2 & $12.0-16.0$ & $\mathrm{~d} / \mathrm{dL}$ \\
\hline Leucocyte & 8,500 & $4,000-10,000$ & $/ \mathrm{uL}$ \\
\hline Platelets & 227,000 & $150,000-400,000$ & $/ \mathrm{uL}$ \\
\hline SGOT & 29 & $5-34$ & $\mathrm{U} / \mathrm{L}$ \\
\hline SGPT & 34 & $<55$ & $\mathrm{U} / \mathrm{L}$ \\
\hline Random blood glucose & 149 & $80-180$ & $\mathrm{mg} / \mathrm{dL}$ \\
\hline Ureum & 32 & $10-50$ & $\mathrm{mg} / \mathrm{dL}$ \\
\hline Creatinine & 1.26 & $0.6-1.1$ & $\mathrm{mg} / \mathrm{dL}$ \\
\hline Estimated GFR & 43 & & $\mathrm{~mL} / \mathrm{min} / 1.73 \mathrm{~m}^{2}$ \\
\hline Sodium & 138 & 135-145 & $\mathrm{mmol} / \mathrm{L}$ \\
\hline Potassium & 3.4 & $3.5-5.0$ & $\mathrm{mmol} / \mathrm{L}$ \\
\hline Chloride & 105 & $97-111$ & $\mathrm{mmol} / \mathrm{L}$ \\
\hline D-Dimer & 7,720 & $0-550$ & $\mathrm{ng} / \mathrm{mL}$ \\
\hline Albumin & 3.3 & $3.5-5.0$ & $\mathrm{~g} / \mathrm{dL}$ \\
\hline Osmolality & 285 & $280-295$ & $\mathrm{mOsmol} / \mathrm{kg} \mathrm{H} \mathrm{H}_{2} \mathrm{O}$ \\
\hline NT-proBNP & 10,958 & $<300$ & $\mathrm{pg} / \mathrm{mL}$ \\
\hline $\mathrm{HbA}_{1 \mathrm{C}}$ & 8.3 & $<6.0$ & $\%$ \\
\hline
\end{tabular}

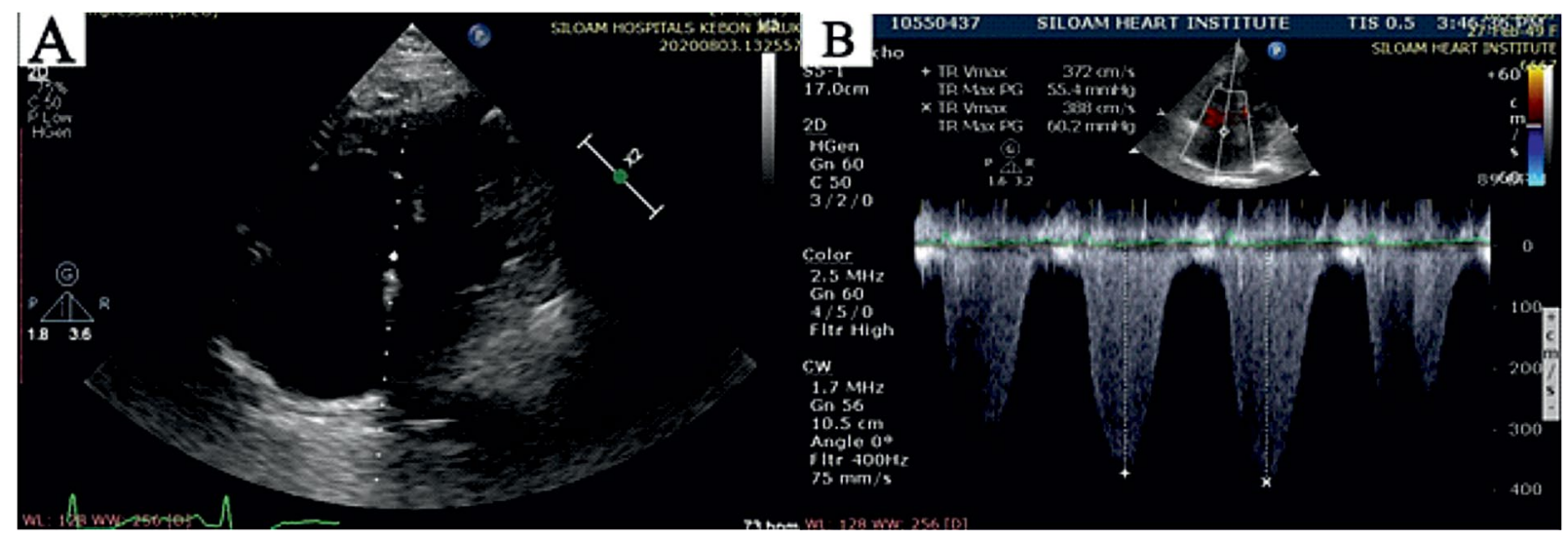

Figure 1. Echocardiography findings. A. Remarkable right ventricular enlargement seen from the apical 4-chamber view. B. Maximum velocity of the tricuspid regurgitation was around $3.8 \mathrm{~m} / \mathrm{s}$, indicating the tricuspid valve gradient of $60 \mathrm{~mm} \mathrm{Hg}$

$\mathrm{mg} / \mathrm{d}$ in order to treat DVT as well as her long-standing hypertension and diabetes.

At the initial presentation she was obese with body mass index (BMI) around $33 \mathrm{~kg} / \mathrm{m}^{2}$ (body weight: $71 \mathrm{~kg}$, body height: $1.47 \mathrm{~m}$ ), and appeared dyspneic. Her vital signs on admission were as follows: fully awake, blood pressure 103/58 $\mathrm{mm} \mathrm{Hg}$, heart rate $90 \mathrm{bpm}$, respiratory rate $30 / \mathrm{min}$; body temperature $37.0^{\circ} \mathrm{C}$, and oxygen saturation $93 \%$ at room air. Other findings included slightly increased jugular vein pressure, increased the second heart sound without any murmur, clear lung sound, and swelling with tenderness at the entire right leg. ECG showed sinus tachycardia and diffuse ST depression at anteroseptal leads. Abnormalities on the initial labora- tory results included increased D-Dimer $7,720 \mathrm{ng} / \mathrm{mL}$ and NTproBNP 10,958 pg/mL, HbA1C 8.3\%, and slightly elevated creatinine $1.26 \mathrm{mg} / \mathrm{dL}$ (Table 1, Figure 1).

Echocardiography revealed normal left ventricle (LV) structure and preserved systolic function, an estimated pulmonary artery systolic pressure (PASP) of 70-80 $\mathrm{mm} \mathrm{Hg}$, prominent systolic septal inversion of $\mathrm{LV}$, dilated RV, slightly reduced right ventricular systolic function. An obstructive thrombus with non-compressible vein were seen by Duplex Ultrasound upon right common femoral vein. Eventually, CT angiography of pulmonary artery confirmed the diagnosis of acute pulmonary embolism caused by several thrombus at both main branches of pulmonary arteries, along 


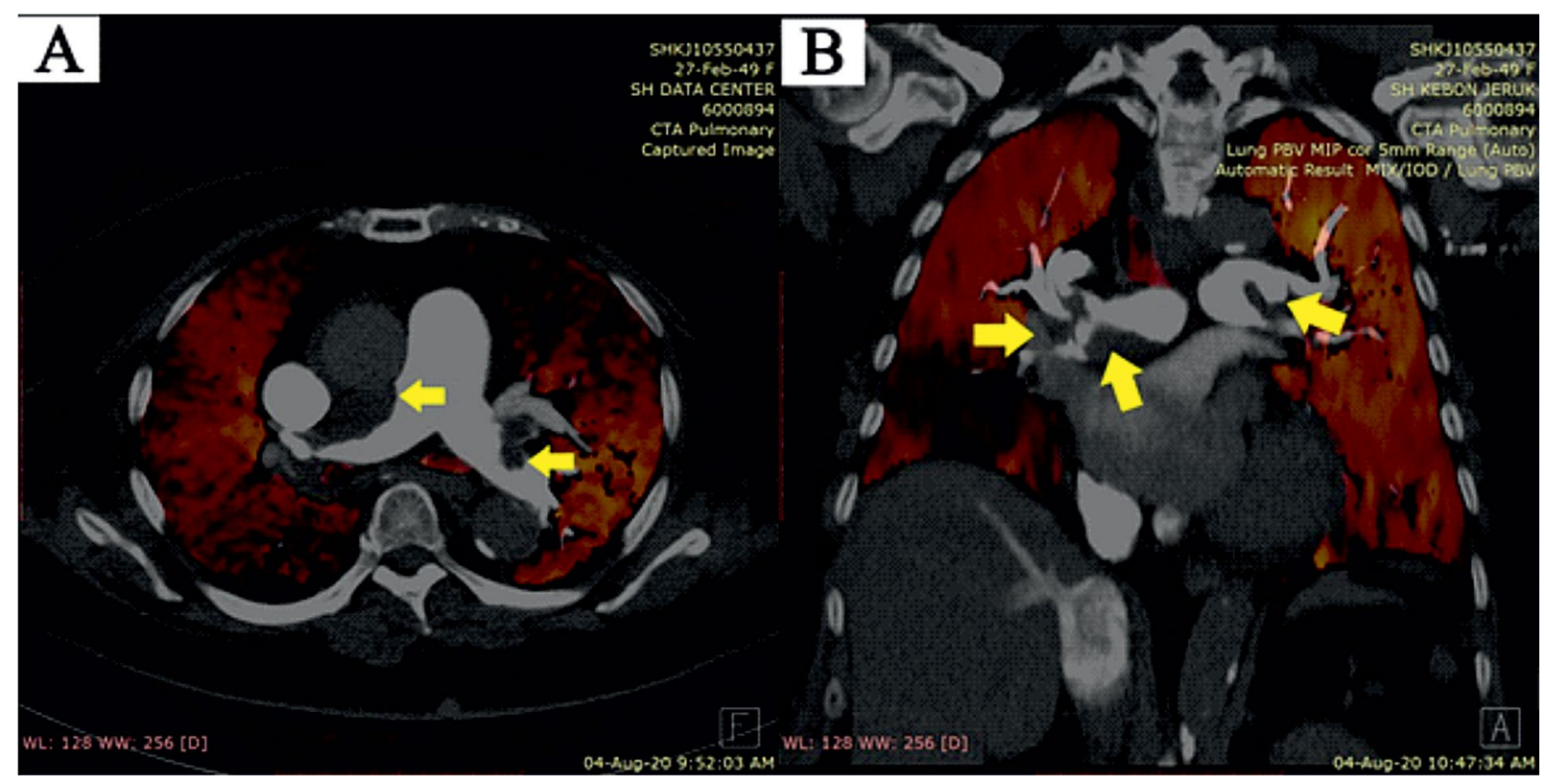

Figure 2. Computed tomography angiography of the pulmonary arteries revealed large thrombus (yellow arrows) at both main branches of pulmonary arteries and the distal branches. A. Axial plane. B. Coronal plane

Table 2. Laboratory results at worsening symptoms

\begin{tabular}{lccc}
\hline Parameters & Value & Reference range & Unit \\
\hline Random blood glucose & 142 & $80-180$ & $\mathrm{mg} / \mathrm{dL}$ \\
Lactic acid & 5.4 & $0.7-2.5$ & $\mathrm{mmol} / \mathrm{L}$ \\
Blood keton & 2.9 & $0.0-0.6$ & $\mathrm{mmol} / \mathrm{L}$ \\
$\mathrm{pH}$ & 7.14 & $7.35-7.45$ & $\mathrm{~mm} \mathrm{Hg}$ \\
$\mathrm{pO}^{2}$ & 75.0 & $80.0-105.0$ & $\mathrm{~mm} \mathrm{Hg}$ \\
$\mathrm{pCO}_{2}$ & 36.7 & $35.0-45.0$ & $\mathrm{mmol} / \mathrm{L}$ \\
Bicarbonate & 12.1 & $21.0-28.0$ & $\mathrm{mmol} / \mathrm{L}$ \\
Base excess & -17.0 & $-2.5 \pm 2.5$ & $\%$ \\
T CO & 13.0 & $19.0-25.0$ & $\mathrm{U} / \mathrm{L}$ \\
O2 Saturation & 88 & $95.0-100$ & $\mathrm{U} / \mathrm{L}$ \\
SGOT & 34 & $5-34$ & $\mathrm{mg} / \mathrm{dL}$ \\
SGPT & 26 & $<55$ & $\mathrm{mg} / \mathrm{dL}$ \\
Ureum & 28 & $10-50$ & $\mathrm{~mL} / \mathrm{min} / 1.73 \mathrm{~m}$ \\
Creatinine & 1.37 & $0.6-1.1$ & $\mathrm{mmol} / \mathrm{L}$ \\
Estimated GFR & 38 & & $\mathrm{mmol} / \mathrm{L}$ \\
Sodium & 141 & $135-145$ & $\mathrm{mmol} / \mathrm{L}$ \\
Potassium & 4.1 & $3.5-5.0$ & $97-111$ \\
Chloride & 111 & & \\
\hline
\end{tabular}

with multiple chronic segmental embolisms. Based on these findings, she was treated with subcutaneous enoxaparin $60 \mathrm{mg}$ bidaily and high-flow nasal oxygen (Optiflow) (Figure 2).

During the next 48 hours, she developed increased work of breathing and loss of consciousness, although the hemodynamic and oxygenation remained stable, urging her to get intubated and mechanical ventilated. The blood test showed random blood glucose $142 \mathrm{mg} / \mathrm{dL}$, $\mathrm{pH} 7.14$, base excess -17, $\mathrm{pCO}_{2} 36.7 \mathrm{~mm} \mathrm{Hg}$, calculated anion gap $17.9 \mathrm{mEq} / \mathrm{L}$, as well as increased levels of blood ketone $2.9 \mathrm{mmol} / \mathrm{L}$ and lactate $5.5 \mathrm{mmol} / \mathrm{L}$. Notably, her urea and creatinine levels were relative steady at $28 \mathrm{mg} / \mathrm{dL}$ and $1.37 \mathrm{mg} / \mathrm{dL}$, respectively (Table 2). 
Table 3. Laboratory results after insulin administration and other corrections

\begin{tabular}{|c|c|c|c|}
\hline Parameters & Value & Reference range & Unit \\
\hline Random blood glucose & 136 & $80-180$ & $\mathrm{mg} / \mathrm{dL}$ \\
\hline Lactic acid & 1.6 & $0.7-2.5$ & $\mathrm{mmol} / \mathrm{L}$ \\
\hline Blood keton & 0.2 & $0.0-0.6$ & $\mathrm{mmol} / \mathrm{L}$ \\
\hline $\mathrm{pH}$ & 7.54 & $7.35-7.45$ & \\
\hline $\mathrm{pO}_{2}$ & 92.9 & $80.0-105.0$ & $\mathrm{~mm} \mathrm{Hg}$ \\
\hline $\mathrm{pCO}_{2}$ & 28.6 & $35.0-45.0$ & $\mathrm{~mm} \mathrm{Hg}$ \\
\hline Bicarbonate & 25.0 & $21.0-28.0$ & $\mathrm{mmol} / \mathrm{L}$ \\
\hline Base excess & 3.8 & $-2.5 \pm 2.5$ & \\
\hline $\mathrm{T} \mathrm{CO}_{2}$ & 25.8 & $19.0-25.0$ & $\mathrm{mmol} / \mathrm{L}$ \\
\hline $\mathrm{O}_{2}$ Saturation & 98.2 & $95.0-100$ & $\%$ \\
\hline Ureum & 26 & $10-50$ & $\mathrm{mg} / \mathrm{dL}$ \\
\hline Creatinine & 1.35 & $0.6-1.1$ & $\mathrm{mg} / \mathrm{dL}$ \\
\hline Estimated GFR & 39.5 & & $\mathrm{~mL} / \mathrm{min} / 1.73 \mathrm{~m}^{2}$ \\
\hline Sodium & 145 & $135-145$ & $\mathrm{mmol} / \mathrm{L}$ \\
\hline Potassium & 4.5 & $3.5-5.0$ & $\mathrm{mmol} / \mathrm{L}$ \\
\hline Chloride & 109 & $97-111$ & $\mathrm{mmol} / \mathrm{L}$ \\
\hline
\end{tabular}

Meanwhile, there was no significant ECG changes than the previous recording, except sinus tachycardia. Moreover, follow-up echocardiography indicated improvement of right ventricular size and function, and reduced PASP (around 55-65 $\mathrm{mm} \mathrm{Hg}$ ) as well.

A diagnosis of Eu-DKA presumably related to empagliflozin was considered. Empagliflozin was withheld, then rehydration and administration of bicarbonate as well as small dose of insulin drip along with dextrose solution were managed. Rapid resolution of metabolic acidosis, lactate and ketone levels along with the clinical improvement was achieved on the following days (Table 3). Predischarge echocardiography demonstrated reduction of PASP to 55-65 $\mathrm{mm} \mathrm{Hg}$ and right ventricle size, as well as an increased tricuspid annular plane systolic excursion (TAPSE). Finally, she was discharged in the next week with rivaroxaban $20 \mathrm{mg}$ od., sildenafil $25 \mathrm{mg}$ tid., and atorvastatin $20 \mathrm{mg} / \mathrm{d}$.

\section{Discussion}

Here, we presented a case of Eu-DKA occurred in patients admitted due to acute pulmonary embolism (PE). Regarding to the steady hemodynamic and oxygenation status, her clinical deterioration during hospitalization was more likely caused by the progression of metabolic acidosis, rather than the PE progression. Recent use of empagliflozin might contribute in developing DKA in this critical case.

Since symptoms of Eu-DKA are less typical compared to classical DKA, early recognition of this complication might be challenging [3]. Potential precipitating factors of developing Eu-DKA in SGLT2i use include low carbohydrate diets, restricted fluid intake, concomitant critical diseases (including acute pulmonary embolism), malnutrition, pregnancy, excessive alcohol intake, and insulin withdrawal or dose reduction [4-6].

Notably, lean individuals on SGLT2i have a higher risk compared with obese individuals since the degree of glycosuria is independent of body size [7]. In addition, type-2 diabetes mellitus patients with limited -cell function reserves, longer duration of diabetes, and poorer control of diabetes are also more prone to experience Eu-DKA [8].

The reported incidences of DKA in previous studies of SGLT2i are low, however the specific numbers of Eu-DKA events were not certainly assessed. The CANagliflozin cardioVascular Assessment Study (CANVAS) noted the incidences of this catastrophe in canagliflozin group compared to the placebo are 0.6 versus 0.3 per 1000 patients, respectively [7]. Other study, the Empagliflozin Cardiovascular Outcome Event Trial in Type 2 Diabetes Mellitus Patients-Removing Excess Glucose (EMPA-REG OUCTOME) showed the incidence of DKA is less than $0.1 \%$. Similar to EMPA-REG OUTCOME, the Dapagliflozin Effect of Cardiovascular Events (DECLARE) also reported the frequencies of DKA is $<0.1 \%[3,7]$. Moreover, FDA indicated that the fatality rate of Eu-DKA associated SGLT2 $\mathrm{i}$ is higher compared to classical DKA (1.54\% and $0.4 \%$, respectively) [9].

Eu-DKA in the setting of SGLT2i use is directly related to the effect of glycosuria of this agent [10]. SGLT2 $\mathrm{i}$ increase glucose excretion contributing to approximately $50-100 \mathrm{mg} /$ day. As a result, the plasma glucose levels are reduced after a meal and in fasting 
state [3]. Furthermore, the plasma insulin levels are also reduced because glucose is the stimulus of insulin release. In contrast, the plasma glucagon levels are increased. The possible mechanisms of increased plasma glucagon levels are diminished paracrine inhibition of insulin and decreased SGLT-2 mediated glucose transport into pancreatic $\alpha$-cells [5, 11]. Dapagliflozin had been considered for having a direct effect on pancreatic $\alpha$-cells by triggering glucagon secretion, but this finding varies between studies $[12,13]$. Recent study reported interindividual differences of SGLT2 protein expression and function in human pancreatic islet, which support the explanation of interindividual response among individuals with SGLT2i [14].

The reduced plasma insulin levels and increased plasma glucagon levels result in an reduced insulin-toglucagon ratio [8]. Given that insulin have anti-lipolytic activity, lower insulin-to-glucagon ratio would potentially induce lipolysis contributing to an increased release of free fatty acid (FFA). The elevated FFA delivery to the liver might cause an increased ketone production [3, 9]. Moreover, reduced insulin levels would bring down the activity of acetyl-CoA carboxylase and then result in declined malonyl-CoA levels, a potent inhibitor of carnitine palmitoyl-transferase-I (CPT-I). This process will end up in an increased CPT-I which further promotes the transport of FFA into mitochondria and oxidation of FFA to ketone bodies, including acetoacetate and $\beta$-hydroxybutyrate $[4,7,9]$.

To date, there is no specific guideline for the treatment of Eu-DKA associated SGLT2i. Basically, the approach refers to management of the classical DKA, except there is no hyperglycemia in this case [7, 9]. SGLT2i are needed to be withheld for a period of time, and intravenous isotonic fluid administration might be considered to replenish volume status $[12,13]$. If the potassium level is more than $3.3 \mathrm{mEq} / \mathrm{L}$, intravenous insulin can be safely given along with intravenous dextrose $5 \%$ to avoid hypoglycaemia $[3,5]$. Bicarbonate usually is considered in severe metabolic acidosis indicated by $\mathrm{pH}$ level less than 6.9 [15]. The resolution of Eu-DKA is marked by 2 of the following conditions, a serum bicarbonate level $\geq 15 \mathrm{mmol} / \mathrm{L}$, and anion gap $\leq 12 \mathrm{mmol} / \mathrm{L}$, or venous $\mathrm{pH}>7.3$ [10].

\section{Conclusion}

Eu-DKA might potentially occur in diabetic patients treated with SGLT2i during critical illness setting. Prompt recognition of this atypical clinical condition is paramount important to intervene this life-threatening complication.

\section{Conflict of interest \\ None declared.}

\section{REFERENCES}

1. Ogawa W, Sakaguchi K. Euglycemic diabetic ketoacidosis induced by SGLT2 inhibitors: possible mechanism and contributing factors. J Diabetes Investig. 2016; 7(2): 135-138, doi: 10.1111/jdi.12401, indexed in Pubmed: 27042263.

2. Wang KM, Isom RT. SGLT2 inhibitor-induced euglycemic diabetic ketoacidosis: a case report. Kidney Med. 2020; 2(2): 218-221, doi: 10.1016/j.xkme.2019.12.006, indexed in Pubmed: 32734242.

3. Rosenstock J, Ferrannini E, Rosenstock J, et al. Euglycemic diabetic ketoacidosis: a predictable, detectable, and preventable safety concern with SGLT2 inhibitors. Diabetes Care. 2015; 38(9): 16381642, doi: 10.2337/dc15-1380, indexed in Pubmed: 26294774.

4. Barski L, Eshkoli T, Brandstaetter E, et al. Euglycemic diabetic ketoacidosis. Eur J Intern Med. 2019; 63: 9-14, doi: 10.1016/j. ejim.2019.03.014, indexed in Pubmed: 30910328.

5. Benmoussa J, Clarke M, Penmetsa A, et al. Euglycemic diabetic ketoacidosis: The clinical concern of SGLT2 inhibitors. Journal of Clinical and Translational Endocrinology: Case Reports. 2016; 2: 17-19, doi: 10.1016/j.jecr.2016.05.002.

6. Candelario N, Wykretowicz J. The DKA that wasn't: a case of euglycemic diabetic ketoacidosis due to empagliflozin. Oxf Med Case Reports. 2016; 2016(7): 144-146, doi: 10.1093/omcr/omw061, indexed in Pubmed: 27471597.

7. Sampani E, Sarafidis P, Papagianni A. Euglycaemic diabetic ketoacidosis as a complication of SGLT-2 inhibitors: epidemiology, pathophysiology, and treatment. Expert Opin Drug Saf. 2020; 19(6): 673-682, doi: 10.1080/14740338.2020.1764532, indexed in Pubmed: 32521174.

8. Yu X, Zhang S, Zhang L. Newer perspectives of mechanisms for euglycemic diabetic ketoacidosis. Int J Endocrinol. 2018; 2018: 7074868, doi: 10.1155/2018/7074868, indexed in Pubmed: 30369948.

9. Diaz-Ramos A, Eilbert W, Marquez D. Euglycemic diabetic ketoacidosis associated with sodium-glucose cotransporter-2 inhibitor use: a case report and review of the literature. Int J Emerg Med. 2019; 12(1): 27, doi: 10.1186/s12245-019-0240-0, indexed in Pubmed: 31488052.

10. Peters AL, Buschur EO, Buse JB, et al. Euglycemic diabetic ketoacidosis: a potential complication of treatment with sodium-glucose cotransporter 2 inhibition. Diabetes Care. 2015; 38(9): 16871693, doi: 10.2337/dc15-0843, indexed in Pubmed: 26078479.

11. Goldenberg RM, Berard LD, Cheng AYY, et al. SGLT2 Inhibitorassociated Diabetic Ketoacidosis: Clinical Review and Recommendations for Prevention and Diagnosis. Clin Ther. 2016; 38(12): 2654-2664.e1, doi: 10.1016/j.clinthera.2016.11.002, indexed in Pubmed: 28003053.

12. Bonner C, Kerr-Conte J, Gmyr V, et al. Inhibition of the glucose transporter SGLT2 with dapagliflozin in pancreatic alpha cells triggers glucagon secretion. Nat Med. 2015; 21(5): 512-517, doi: 10.1038/nm.3828, indexed in Pubmed: 25894829.

13. Kuhre RE, Ghiasi SM, Adriaenssens $A E$, et al. No direct effect of SGLT2 activity on glucagon secretion. Diabetologia. 2019; 62(6): 1011-1023, doi: 10.1007/s00125-019-4849-6, indexed in Pubmed: 30903205.

14. Saponaro C, Mühlemann M, Acosta-Montalvo A, et al. Interindividual heterogeneity of SGLT2 expression and function in human pancreatic islets. Diabetes. 2020; 69(5): 902-914, doi: 10.2337/ db19-0888, indexed in Pubmed: 31896553.

15. Bonora BM, Avogaro A, Fadini GP. Euglycemic ketoacidosis. Curr Diab Rep. 2020; 20(7): 25, doi: 10.1007/s11892-020-01307-x, indexed in Pubmed: 32424730. 